\section{Effects of Zoledronic Acid in Experimental PeriapicalLesionsin Rats: An Imaging and Histological Analysis}

Talita Ribeiro Tenório de França1', Flávia Maria de Moraes Ramos-Perez¹, Andrea dos Anjos Pontual' ${ }^{1}$ Jurema Freire Lisboa de Castro ${ }^{1}$, Paulo Rogério Ferreti Bonan², Danyel Elias da Cruz Perez ${ }^{1}$
'School of Dentistry, Department of Clinic and Preventive Dentistry, UFPE: Universidade Federal de Pernambuco, Recife, PE, Brazil ${ }^{2}$ Department of Stomatology, UFPB: Universidade Federal da Paraíba, João Pessoa, PB, Brazil

Correspondence: Danyel Elias da Cruz Perez, 4a Travessa Professor Artur de Sá, s/n, Cidade Universitária 50740-521 Recife, PE, Brazil. Tel: +55-81-2126-7510. e-mail: danyel.perez@ufpe.br
The aim of this study was to assess the imaging and histological features of experimental periapical lesions, including the adjacent alveolar bone, in rats under zoledronic acid treatment. The study used 40 male Wistar rats distributed into 8 groups of 5 animals each: G1: induction of periapical lesion (PL) and weekly intraperitoneal administration (WIPA) of saline solution $(0.9 \% \mathrm{NaCl})$ for 4 weeks; $\mathrm{G} 2$ : PL induction and WIPA of zoledronic acid $(0.15 \mathrm{mg} / \mathrm{kg} /$ week) for 4 weeks; G3: PL induction and WIPA of saline solution for 8 weeks; G4: PL induction and WIPA of zoledronic acid for 8 weeks; G5:WIPA of saline solution for 4 weeks and subsequent PL induction; G6: WIPA of zoledronic acid for 4 weeks and subsequent PL induction; G7: WIPA of saline solution for 8 weeks and subsequent PL induction; G8: WIPA of zoledronic acid for 8 weeks and subsequent PL induction. The administration of zoledronic acid or saline solution continued after PL induction until the euthanasia. Thus, cone beam computed tomography and histological analysis were performed. Statistical analyzes were performed by ANOVA and Kruskal-Wallis test. Groups treated with zoledronic acid showed significantly smaller size of PL than the groups treated with $0.9 \% \mathrm{NaCl}(p<0.05)$. PLs were formed by chronic inflammation ranging from mild to moderate, with no difference between groups. In all specimens, no mandibular necrosis was observed. In conclusion, the presence of PLs apparently does not represent an important risk factor for the development of bisphosphonate-related osteonecrosis of the jaws.
Key Words: bisphosphonates; bisphosphonate-related osteonecrosis of the jaws; Endodontics; periapical lesions; zoledronic acid.

\section{Introduction}

Bisphosphonates (BP) are pyrophosphoric acid analogues. These drugs have high affinity for bone tissue and act by inhibiting the activity of osteoclasts and consequently, the bone resorption (1-3). Similar to pyrophosphate, the BP bind strongly to the hydroxyapatite crystals. Once bound to the bone, BP inhibit bone resorption and remain non-metabolized for long periods. During bone turnover, BP is phagocytosed by osteoclasts, inducing changes in cellular morphology and apoptosis of osteoclasts (4). This results in decreasing of osteoclastic activity on the bone surface. BP also acts by inhibiting RANKL expression and induces osteoblasts to produce osteoprotegerin (OPG), which competes with RANKL for RANK. The synthesis of OPG leads to a decreasing in osteoclastic activity (5). Because of their anti-resorptive action, BP are used in the treatment of bone diseases, such as osteoporosis, osteopenia, Paget disease, hypercalcemia associated with cancer, multiple myeloma, and bone metastases (1-3).

Although BP are effective in the treatment of resorptive bone diseases, they may cause local and systemic adverse side effects. The most significant local adverse side effect is the bisphosphonates-related osteonecrosis of the jaw (BRONJ). BRONJ is characterized by necrosis of the mandible or maxilla in patients taking bisphosphonates (BP) and not exposed to radiotherapy in the head and neck region (1). BP are used in the treatment of bone diseases, such as osteoporosis, osteopenia, Paget disease, hypercalcemia associated with cancer, multiple myeloma, and bone metastases (1-3). Studies have shown some risk factors that are significant for the development of BRONJ, such as type of BP, route of administration (oral or endovenous), number of infusions, age and dental extractions (1-3). BRONJ usually occurs after an invasive dental procedure, but it can also happen spontaneously (6). Recent multicenter study revealed that the time of onset of BRONJ is 2.2 years of treatment with zoledronic acid and 6.0 years of treatment with alendronate (2). Currently, there has been a trend towards replacing the term BRONJ by osteonecrosis of the jaws in order to comprise the growing number of cases of osteonecrosis associated with the use of other antiresorptive and antiangiogenic drugs (1). Among these cases of osteonecrosis, BP represents the most important group.

Although some risk factors are well established in the literature, others remain unclear, mainly local risk factors. 
Evidence about periapical lesions acting as a risk factor is limited. There are only some reports in the literature showing BRONJ triggered by conservative endodontic procedures (7-9). Animal models have been also used to evaluate whether periapical lesions can be considered a risk factor for development of BRONJ. Xiong et al. (10) evaluated the effects of administration of alendronate in the alveolar bone resorption processes in rats with periapical lesions. They observed that administration of BP inhibited bone resorption associated with apical periodontitis. However, they did not diagnose any ulcers or osteonecrosis. On the other hand, Kang et al. (11) evaluated the effect of zoledronic acid on periapical lesions in rats and found BRONJ cases in these animals.

The inhibitory effect of BP on bone remodeling can also potentially interfere with periradicular healing during root canal therapy. However, the effect of BP on the onset and evolution of periapical lesions (12), and whether these lesions represent a potential local risk factor for BRONJ (11) have not been clearly explained. Thus, the aim of this study was to assess the imaging and histological features of experimental periapical lesions, including the surrounding adjacent alveolar bone, in rats under zoledronic acid treatment.

\section{Material and Methods}

This study was approved by the Local Ethics Committee on Animal Use (protocol \# 23076.027486/2010-25). Forty male rats (Rattus novergicus, albinus Wistar), weighing between 220 and 250 grams were used. The animals were randomly divided into 8 groups with 5 animals each, being 4 experimental groups and 4 control groups.

The animals in the experimental groups were treated with $0.15 \mathrm{mg} / \mathrm{kg}$ of zoledronic acid once a week (Zometa, Novartis Pharmaceuticals, Basel, Switzerland), administered intraperitoneally, while control groups were treated with $0.5 \mathrm{~mL}$ of saline solution $(0.9 \% \mathrm{NaCl})$ once time a week, administered intraperitoneally. In the groups G5, G6, G7 and $\mathrm{G} 8$, in which the administration of zoledronic acid or saline solution was performed before the periapical lesions induction, the administration of the drug or saline solution continued after periapical lesions induction until the euthanasia. The animals of the groups $\mathrm{G} 2$ and $\mathrm{G} 4$ were treated with zoledronic acid after the induction of periapical lesion, totalizing 4 and 8 weeks of treatment, respectively. On the other hand, the animals of the groups G6 and G8 were treated with zoledronic acid before the periapical lesion induction, totalizing 8 and 12 weeks of treatment, respectively. The distribution of the experimental and control groups according to the sequence of administration of zoledronic acid or saline solution is described in Table 1.

In order to induce periapical lesions, the pulps of the right mandibular first molars were exposed on the occlusal mesial surface using a $1 / 2$ round bur in a highspeed handpiece, under water cooling. The dental pulps remained exposed in the oral cavity for 30 days. Prior to pulp exposure, the animals were anesthetized with ketamine hydrochloride $0.1 \mathrm{mg} / \mathrm{kg}$ (SESP, Vetbrands Animal Health Division, Jacarei, São Paulo, Brazil) associated with xylazine $0.05 \mathrm{mg} / \mathrm{kg}$ (Bayer Brazil, Belford Roxo, Rio de Janeiro, Brazil), intramuscularly.

After the period of analysis in each group, the animals were euthanized by anesthetic overdose with ketamine hydrochloride and xylazine. The mandibles were dissected and placed in plastic receptacles containing $10 \%$ formaldehyde solution. In these receptacles, the specimens were submitted to cone-beam computed tomography (CBCT) (i-CAT Next Generation, Imaging Sciences International, Hatfield, PA), operating at $120 \mathrm{kV}$ and $3.8 \mathrm{~mA}$, using a protocol with voxel size of $0.2 \mathrm{~mm}$ and an exposure time of 26 seconds. Afterwards, images were reconstructed and evaluated using the XORAN software (Xoran CAT version 2.0.21, Xoran Technologies, Ann Arbor Mich, USA). The images were analyzed in multiplanar reconstructions (axial, sagittal and coronal) by an Oral Radiology specialist with experience in the method used. The measurement was taken in the largest diameter of the lesions in each specimen analyzed, using the same software on a 22"flat screen monitor (Dell Precision 390 ${ }^{\mathrm{TM}}$, Dell Inc., Round Rock, Texas, USA). Image density and contrast were adjusted accordingly to help the observer.

After imaging analyses, the jaws were decalcified in $5.0 \%$ aqueous solution of ethylenediaminetetracetic acid (EDTA). Histological sections $5-\mu \mathrm{m}$ thick were obtained from tissue-embedded paraffin blocks and stained with hematoxylin-eosin (HE). Microscopically, the inflammatory reaction in the periapical lesions was classified as mild (scarce inflammatory reaction), moderate (focal intense inflammatory reaction) or severe (diffuse intense inflammatory reaction). For mild inflammation was attributed score 1, score 2 for moderate inflammation, and score 3 for severe inflammation. Moreover, the adjacent alveolar bone was histologically evaluated. Six serial sections stained in hematoxylin and eosin were scanned by Pannoramic MIDI digital slide scanner (3Dhistech $\mathrm{Kft}$, Budapest, BP, Hungary), and analyzed using Pannoramic Viewer software (3Dhistech Kft, Budapest, BP, Hungary). Empty bony lacunae were counted. Osteonecrosis was defined as loss of more than five contiguous osteocytes in the alveolar bone adjacent to periapical lesions (13).

The histological and imaging data were analyzed by descriptive statistics. The inflammation intensity and imaging data that showed normal distribution were analyzed by ANOVA and for those that showed non- 
homogeneous distribution, the nonparametric KruskalWallis test was used, considering a $5 \%$ level of significance .Statistical calculations were performed with SAS 9.2 software (Cary, North Carolina, USA).

\section{Results}

In the control and zoledronic acid groups, no ulcers or osteonecrosis with exposed bone were observed during clinical examination after the mandibles were removed and examined. Periapical lesions were evident in the periapical area after pulp exposure in all animals studied. These lesions were identified by CBCT and histopathological analysis.

Imaging analysis by CBCT revealed periapical lesions associated with the right mandibular first molars in all animals. The groups treated with zoledronic acid $(G 2, G 4$, G6 and G8) showed periapical lesions with a significantly smaller size than those in the groups treated with $0.9 \%$ $\mathrm{NaCl}(\mathrm{G} 1, \mathrm{G} 3 \mathrm{G} 5$ and G7), respectively ( $p<0.0001)$ (Fig. 1).

Table 1 shows the mean size (in millimeters) of periapical lesions in the control and treated animals. When analyzing the matching control and experimental groups, the comparison revealed that the control groups $\mathrm{G} 1, \mathrm{G} 3$ and G7 presented significantly larger periapical lesions than the experimental groups G2 ( $p=0.0009), G 4(p=0.0015)$ and $\mathrm{G} 8(\mathrm{p}=0.0078)$, respectively. Although the specimens of $\mathrm{G} 5$ presented periapical lesions larger than those in $\mathrm{G} 6$, this difference was not significant ( $p=0.0736)$.

Among the control groups (G1, G3, G5 and G7), the size of periapical lesions were statistically different $(p=$ 0.0026). The groups $G 1$ and $G 3$, in which the periapical lesions were induced and saline solution applications were subsequently performed, showed larger periapical lesions

Table 1. Distribution of the experimental and control groups according to the sequence of administration of zoledronic acid or saline solution

\begin{tabular}{|c|c|}
\hline Groups & Procedures \\
\hline G1 & $\begin{array}{c}\text { Induction of PL and administration } \\
\text { of } 0.9 \% \mathrm{NaCl} \text { for } 4 \text { weeks }\end{array}$ \\
\hline G2 & $\begin{array}{l}\text { Induction of PL and administration } \\
\text { of zoledronic acid for } 4 \text { weeks }\end{array}$ \\
\hline G3 & $\begin{array}{c}\text { Induction of PL and administration } \\
\text { of } 0.9 \% \mathrm{NaCl} \text { for } 8 \text { weeks }\end{array}$ \\
\hline G4 & $\begin{array}{l}\text { Induction of PL and administration } \\
\text { of zoledronic acid for } 8 \text { weeks }\end{array}$ \\
\hline G5 & $\begin{array}{l}\text { Administration of } 0.9 \% \mathrm{NaCl} \\
\text { for } 4 \text { weeks and induction of } \mathrm{PL}\end{array}$ \\
\hline G6 & $\begin{array}{l}\text { Administration of zoledronic acid } \\
\text { for } 4 \text { weeks and induction of PL }\end{array}$ \\
\hline G7 & $\begin{array}{l}\text { Administration of } 0.9 \% \mathrm{NaCl} \\
\text { for } 8 \text { weeks and induction of PL }\end{array}$ \\
\hline G8 & $\begin{array}{l}\text { Administration of zoledronic acid } \\
\text { for } 8 \text { weeks and induction of PL }\end{array}$ \\
\hline
\end{tabular}

(Table 1). In the same way, in the animals treated with zoledronic acid (G2, G4, G6 and G8), the size of periapical lesions were statistically different $(p<0.0001)$. The groups $\mathrm{G} 2$ and $\mathrm{G} 4$, in which the periapical lesions were induced first and then the administration of zoledronic acid began, showed larger periapical lesions (Table 2).

Microscopically, in all specimens, the chronic periapical lesions were well circumscribed and consisted of a fibrous connective tissue infiltrated by chronic inflammatory reaction ranging from mild to moderate intensity, formed predominantly by lymphocytes. The inflammatory cells appeared dispersed into connective tissue, without the presence of large cell clusters. Necrosis or any other morphological alteration were not observed. No differences were observed between the groups analyzed regarding to intensity of the inflammatory reaction $(p=0.2)$. No necrosis was observed in the adjacent bone tissue in any of the samples (Figs. 2, 3, and 4).

\section{Discussion}

The mechanism of BRONJ development has not yet been fully elucidated, but the presence of periodontal disease and dentoalveolar surgeries are among the local risk factors most commonly related (6). Evidence about periapical lesions acting as a risk factor is limited. There are some reports showing BRONJ caused by conservative endodontic procedures (7-9), and an experimental study in rats that showed evidence of bone osteonecrosis in areas adjacent to inflammatory periapical lesions (11). Despite this, the effect of periapical lesions on the bone tissue in subjects under treatment with BP has not been clearly explained. Elucidating the pathophysiology of BRONJ is very important to enable endodontic treatment protocols

Table 2. Mean size of the periapical lesions and analysis of matching control and experimental groups at imaging analysis

\begin{tabular}{lcc}
\hline Groups & $\begin{array}{c}\text { Mean size in mm } \\
\text { (minimum-maximum) }\end{array}$ & p value* \\
\hline G1 & $1.72(1.6-2.0)$ & 0.0009 \\
G2 & $1.2(1.0-1.4)$ & \\
G3 & $1.64(1.5-1.8)$ & 0.0015 \\
G4 & $1.2(1.0-1.4)$ & 0.0736 \\
G5 & $1.04(0.8-1.2)$ & \\
G6 & $0.8(0.6-1.0)$ & 0.0078 \\
G7 & $1.44(1.4-1.6)$ & \\
G8 & $0.64(0.4-0.8)$ & \\
\hline
\end{tabular}


to be established for patients using BP. Therefore, until more scientific evidence is available, precaution necessary when performing endodontic treatment in these patients (14).

In order to generate evidence that may help in establishing these protocols, this study observed the behavior of periapical lesions in rats treated with BP. Other studies have also used animal models to simulate what occurs in patients using BP $(13,15-19)$. Most of these researches used tooth extractions and high doses of BP to simulate clinical, radiographic and histologic features of BRONJ (14). Because BRONJ may occur in the absence of tooth extractions, it is relevant to use animal models to simulate other conditions that are also important in dental practices, because they may eventually also act as risk factor for BRONJ. Among these factors are inflammatory periapical lesions.

In this study, the periapical lesions were induced by pulp exposure according to protocols used in the literature (10). Studies have shown that after pulp exposure in rats, osteoclasts in periapical lesions could be found on day 2 and the peak number of these cells would be reached by day 14. In these studies, increasing amounts of inflammatory infiltration and alveolar bone resorption were also observed to occur in the periapical region from day 7 to day $14(20,21)$. Between day 0 and day 20, a period of lesion expansion and bone destruction occurred (21). Based on these studies,
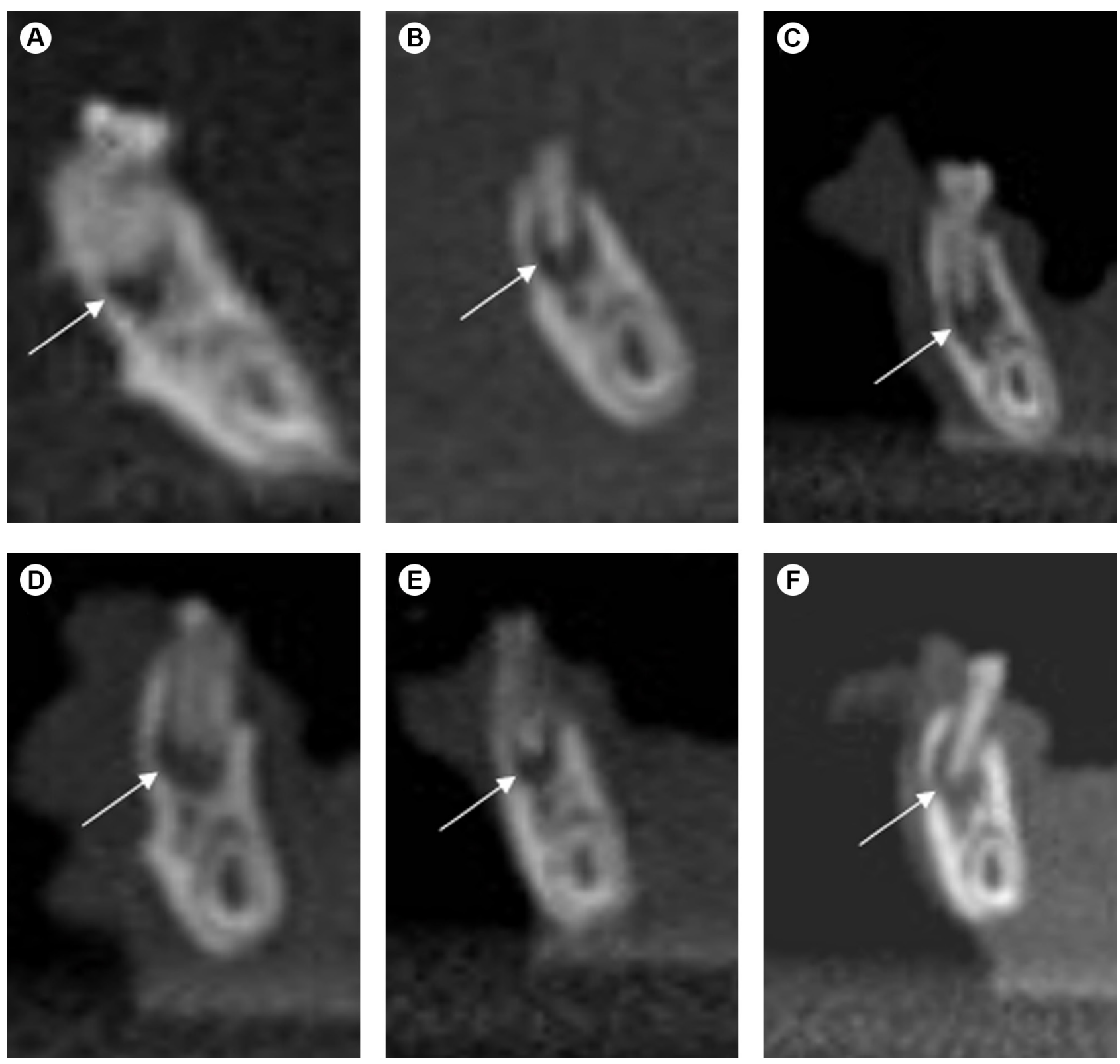

Figure 1. Coronal 0.2-mm-thick reconstructions by cone-beam computed tomography. White arrows indicate periapical lesion in G1 (A), G2 (B), G4 (C), G5 (D), G6 (E) and G8 (F). 
the pulps were exposed in the oral cavity for a period of 30 days to induce periapical lesion.

Although the zoledronic acid is administered intravenously in humans, in the present study it was administered intraperitoneally, similar to the procedures used in other published reports $(11,22)$. In spite of knowing that intraperitoneal administration results in a lower plasmatic concentration of the drug, this way was chosen because it is safer and easier to use in small animals. The doses used in experimental studies vary widely. Ottewel et al. (22) administered a dose of $0.1 \mathrm{mg} / \mathrm{kg}(100 \mu \mathrm{g} / \mathrm{kg})$, and according to these authors, this is equivalent to a human dose of $4 \mathrm{mg} / \mathrm{kg}$ of body weight. Sonis et al. (13) used a dose of $7.5 \mu \mathrm{g} / \mathrm{kg}$, whereas Pautke et al. (19) used the dose of $0.05 \mathrm{mg} / \mathrm{kg}$ of zoledronic acid in minipigs. In this study, we used the dose of $0.15 \mathrm{mg} / \mathrm{kg} /$ week based on the dose of $0.6 \mathrm{mg} / \mathrm{kg} / 28$ days used by Maahs et al. (23). Although it can be considered a high dose, its use has been safety

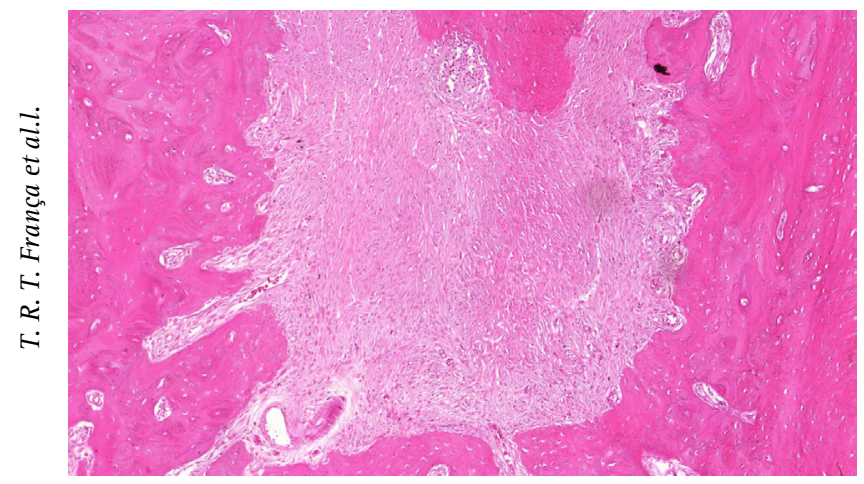

Figure 2. Periapical lesion in control group (0.9\% $\mathrm{NaCl})$. Fibrous connective tissue infiltrated by mild chronic inflammation (HE, $\times 100)$.
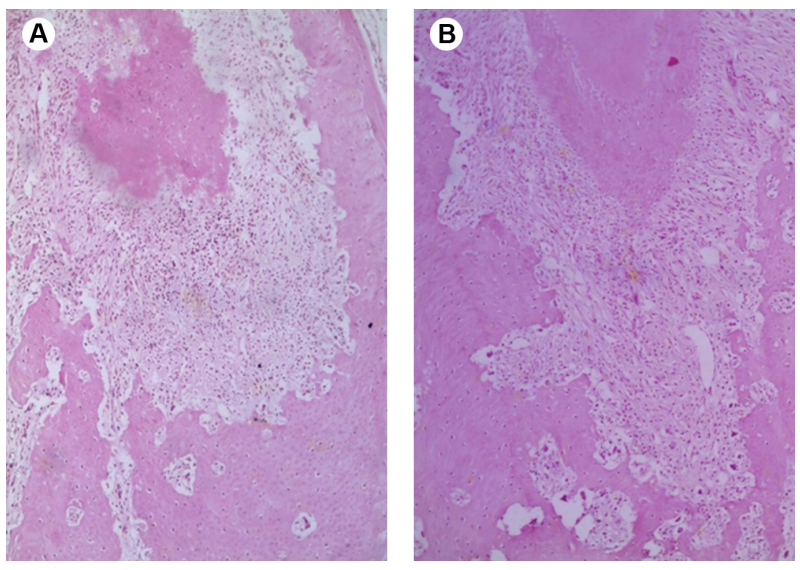

Figure 3. Periapical lesions in experimental groups. A: G2 - Fibrous connective tissue infiltrate with mild chronic inflammatory reaction, composed mainly by lymphocytes. The surrounding alveolar bone is mature, and no necrosis was observed (HE, $\times 50)$. B: G6 - similar histological features observed in the lesion illustrated in A (HE, $\times 50)$. demonstrated in these previous studies and it was chosen to increase the probability of BRONJ in the studied animals.

Some studies observed that inhibition of osteoclast activity resulted in smaller periapical lesions $(11,24)$. Similar to events that occurred in previous experiments, in the present experiment, the periapical lesions in animals treated with zoledronic acid were observed to be significantly smaller than those in animals from the control group. Kang et al. (11) assessed the apices of the molar roots of mouse mandibles by micro-computed tomography scanning and also observed that the size of periapical lesions was significantly smaller in the animals treated with BP. Bone remodeling is an important process in the development, progression and repair of periapical lesions. Since the BP acts by inhibiting bone resorption, its inhibitory effect may interfere in the periapical repair process that occurs during endodontic treatment (12). In the present study, it was proved that in animals treated with BP, periapical lesions tended to be smaller in size than they were in animals that did not receive BP. Clinically, this suggests that patients using BP can have satisfactory periapical healing after endodontic treatment, because the BP did not increase the size of the lesion $(11,12,24)$. However, because of the risk of BRONJ, the systemic use of BP as eventual adjuvant therapy for inflammatory periapical lesions is discouraged. On the other hand, in the future, the use of zoledronic acid nanoparticles in root canal sealers could be a powerful adjuvant treatment in Endodontics.

In the control and experimental groups in which the periapical lesions were induced with subsequent administration of saline solution or zoledronic acid, there were larger periapical lesions, undoubtedly because these lesions presented a longer period of time of progression.
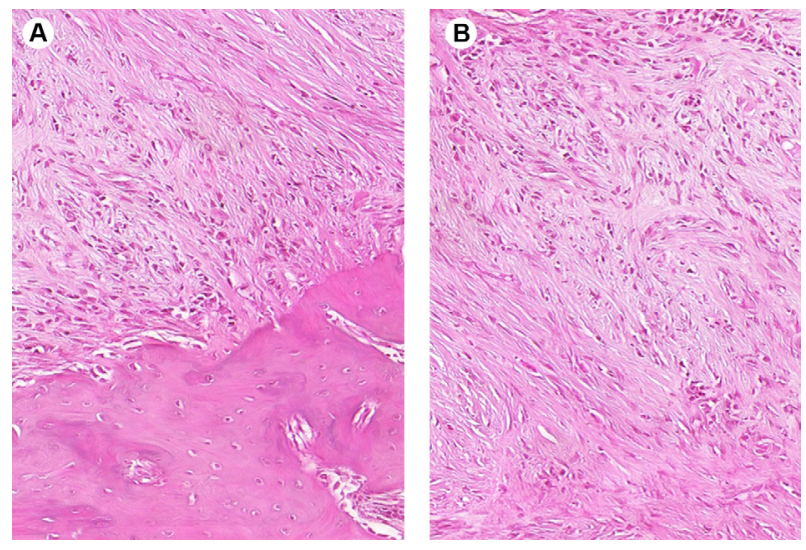

Figure 4. High-power field of periapical lesion in experimental group G8. A: Fibrous connective tissue presenting mild chronic inflammatory reaction, composed mainly by lymphocytes. Adjacent alveolar bone showing well-preserved osteocytes, indicating vital bone (HE, ×200). B: Fibrous connective tissue showing dense fibers and mild inflammation, mainly lymphocytic (HE, ×200). 
However, irrespective of the presence of periapical lesions when the drug administration began, this fact did not influence their evolution and cell population, and the risk of BRONJ. Clinically, this suggests that the appearance of the periapical lesion before or during treatment with $\mathrm{BP}$ does not interfere in the development of these lesions and does not increase the risk of BRONJ.

As regards the histological features, the periapical lesions showed mild to moderate chronic inflammatory reaction, without morphological differences between the all groups. Importantly, even when using high doses of zoledronic acid, no osteonecrosis was observed in any of the specimens. Nevertheless, these results may not be directly translated to humans. Additionally, longer periods of treatment with zoledronic acid must be studied to assess the effects of long-term therapy in inflammatory periapical lesions, and the adjacent alveolar bone. Xiong et al. (10) conducted a study to analyze the effect of alendronate on angiogenesis, and on alveolar bone resorption in rats subjected to experimental periapical lesions. The authors observed no significant decrease in the number of microvascular vessels, and similarly to the present study, no ulcers or BRONJ were observed. On the other hand, Kang et al. (11) observed that $88 \%$ of BP treated animals showed areas of osteonecrosis in the dental disease sites and 33\% developed bone exposure. Moreover, osteonecrosis, periosteal thickening, periosteal bone apposition, epithelial migration and bone exposure were present. However, this high incidence of BRONJ probably occurred because the authors used a threefold higher dose than the zoledronic acid dose used in oncologic patients. Differently, in the present study, pharmacologic doses similar to those used in clinical regimens were administered, which provide a more accurate evaluation of incidence and severity of the disease. Recently, a study observed a diminished progression of periapical lesions in ovariectomized female rats treated with zoledronic acid (25).

Endodontic treatment has been reported to be a risk factor for BRONJ (10). Conversely, other studies claim that endodontic treatment is safe and should be performed in preference to extraction $(6,8)$. However, even if the endodontic treatment is indicated, clinicians need to take some precautions, such as procedures that minimize the trauma to the marginal, apical and periodontal tissues. It is important to pay attention to the periapical radiographs, the position of the clamp and rubber dam, the length of instrumentation and during the root canal filling (7).

According to the present findings, periapical lesions were significantly smaller in animals treated with zoledronic acid. In addition, inflammatory periapical lesions apparently did not represent a significant risk factor for the development of BRONJ, since no ulcers or osteonecrosis of the bone were observed in the mandibles of animals treated with zoledronic acid. Despite this, further scientific evidence is needed in order to provide safe protocols for endodontic treatment of patients who use bisphosphonates.

\section{Resumo}

0 objetivo deste estudo foi avaliar as caracteristicas histológicas e de imagem de lesões periapicais experimentais, incluindo o osso alveolar adjacente, em ratos sob tratamento com ácido zoledrônico. 0 estudo utilizou 40 ratos Wistar, machos, distribuidos em 8 grupos de animais cada: G1: indução de lesão periapical (LP) e administração intraperitoneal semanal (AIS) de solução salina ( $\mathrm{NaCl} 0.9 \%)$ por 4 semanas; $\mathrm{G} 2$ : indução de LP e AIS de ácido zoledrônico $(0,15 \mathrm{mg} / \mathrm{kg} /$ week) por 4 semanas; $\mathrm{G} 3$ : indução de LP e AIS de solução salina por 8 semanas; G4: indução de LP e AIS de ácido zoledrônico por 8 semanas; G5- AIS de solução salina por 4 semanas e subsequente indução de LP; G6- AIS de ácido zoledrônico por 4 semanas e subsequente indução de LP; G7: AIS de solução salina por 8 semanas e subsequente indução de LP; G8: AIS de ácido zoledrônico por 8 semanas e subsequente indução de LP. A administração de ácido zoledrônico ou solução salina continuou após indução de LP até a eutanásia. Após isso, tomografia computadorizada de feixe cônico e análise histológica foram realizadas. Análises estatísticas foram realizadas por ANOVA e teste de Kruskal-Wallis. Os grupos tratados com ácido zoledrônico mostraram LPs significativamente menores que os grupos tratados com $\mathrm{NaCl} 0.9 \%(p<0.05)$. LPs eram formadas por inflamação crônica variando de leve a moderada, sem diferença entre os grupos. Em todos os espécimes, necrose mandibular não foi observada. Em conclusão, a presença de LPs aparentemente não representa um fator de risco importante para o desenvolvimento de osteonecrose relacionada ao uso de bisfosfonatos.

\section{Acknowledgements}

This study was supported by The National Council for Scientific and Technological Development (CNPq), Brazil.

\section{References}

1. Khan AA, Morrison A, Hanley DA, et al. Diagnosis and management of osteonecrosis of the jaw: a systematic review and international consensus. J Bone Miner Res 2015;30:3-23.

2. Fung P, Bedogni G, Bedogni A, Petrie A, Porter S, Campisi G, et al. Time to onset of bisphosphonate-related osteonecrosis of the jaws: a multicentre retrospective cohort study. Oral Dis 2017;23:477-483.

3. Hasegawa T, Kawakita A, Ueda N, Funahara R, Tachibana A, Kobayashi $M$, et al. A multicenter retrospective study of the risk factors associated with medication-related osteonecrosis of the jaw after tooth extraction in patients receiving oral bisphosphonate therapy: can primary wound closure and a drug holiday really prevent MRONJ? Osteoporos Int 2017;28:2465-247.

4. Kikuiri T, Kim I, Yamaza T, Akiyama K, Zhang Q, Li Y, et al. Cell-based immunotherapy with mesenchymal stem cells cures bisphosphonaterelated osteonecrosis of the jaw-like disease in mice. J Bone Miner Res 2010;25:1668-1679.

5. Viereck V, Emons G, Lauck V, Frosch KH, Blaschke S, Gründker C, et al. Bisphosphonates pamidronate and zoledronic acid stimulate osteoprotegerin production by primary human osteoblasts. Biochem Biophys Res Commun 2002;291:680-686.

6. Ruggiero SL, Dodson TB, Fantasia J, Goodday R, Aghaloo T, Mehrotra B, et al. American Association of Oral and Maxillofacial Surgeons position paper on medication-related osteonecrosis of the jaws-2014 update. J Oral Maxillofac Surg 2014;72:1938-1956.

7. Katz H. Endodontic implications of Bisphosphonate-Associated Osteonecrosis of the Jaws: a report of three cases. J Endod 2005;31:831-834. 
8. Sarathy AP, Bourgeois SL, Goodell GG. Bisphosphonate-Associated Osteonecrosis of the Jaws and endodontic treatment: two case reports. J Endod 2005;31:759-763.

9. Gallego L, Junquera L, Pelaz A, Díaz-Bobes $C$. Rubber dam clamp trauma during endodontic treatment: a risk factor of Bisphosphonate-Related Osteonecrosis of the Jaw? J Oral Maxillofac Surg 2011;69:93-95.

10. Xiong $H$, Wei $L, H u Y$, Peng B. Effect of alendronate on alveolar bone resorption and angiogenesis in rats with experimental periapical lesions. Int Endod J 2010;43:485-491.

11. Kang B, Cheong S, Chaichanasakul T, Bezouglaia O, Atti E, Dry SM, et al. Periapical disease and bisphosphonates induce osteonecrosis of the jaws in mice. J Bone Miner Res 2013;28:1631-640.

12. Hsiao $A$, Glickman $G$, He J. A retrospective clinical and radiographic study on healing of periradicular lesions in patients taking oral bisphosphonates. J Endod 2009;35:1525-1528.

13. Sonis ST, Watkins BA, Lyng GD, Lerman MA, Anderson KC. Bony changes in the jaws of rats treated with zoledronic acid and dexamethasone before dental extractions mimic bisphosphonate-related osteonecrosis in cancer patients. Oral Oncol 2009;45:164-172.

14. Moinzadeh AT, Shemesh $H$, Neirynck NA, Aubert C, Wesselink PR. Bisphosphonates and their clinical implications in endodontic therapy. Int Endod J 2013;46:391-398.

15. Bi Y, Gao Y, Ehirchiou D, Cao C, Kikuiri T, Le A et al. Bisphosphonates cause osteonecrosis of the jaw-like disease in mice. Am J Pathol 2010;177:280-290.

16. López-Jornet $P$, Camacho-Alonso $F$, Molina-Miñano $F$, Gómez-Garcia F, Vicente-Ortega V. An experimental study of bisphosphonateinduced jaws osteonecrosis in Sprague-Dawley rats. J Oral Pathol Med 2010;39:697-702.

17. Abtahi J, Agholme F, Sandberg 0, Aspenberg P. Bisphosphonateinduced osteonecrosis of the jaw in a rat model arises first after the bone has become exposed. No primary necrosis in unexposed bone. J Oral Pathol Med 2012;41:494-499.

18. Aguirre Jl, Akhter MP, Kimmel DB, Pingel JE, Williams A, Jorgensen M, et al. Oncologic doses of zoledronic acid induce osteonecrosis of the jaw-like lesions in rice rats (Oryzomyspalustris) with periodontitis. J Bone Miner Res 2012;27:2130-2143.

19. Pautke C, Kreutzer K, Weitz J, Knödler M, Münzel D, Wexel G, et al.. Bisphosphonate related osteonecrosis of the jaw: a minipig large animal model. Bone 2012;51:592-599.

20. Yang L, Zhang C, Peng B. Immunolocalization of tumor necrosis factor receptor-associated factor 6 in rat periapical lesions. J Endod 2009;35:834-837.

21. Lin SK, Hong CY, Chang HH, Chiang CP, Chen $\mathrm{CS}$, Jeng JH, et al. Immunolocalization of macrophages and transforming growth factorbeta1 in induced rat periapical lesions. J Endod 2000;26: 335-340.

22. Ottewell PD, Monkkönen $H_{1}$, Jones $M$, Lefley DV, Coleman RE, Holen I. Antitumor effects of doxorubicin followed by zoledronic acid in a mouse model of breast cancer. J Natl Cancer Inst 2008;100:1167-1178.

23. Maahs MP, Azambuja AA, Campos MM, Salum FG, Cherubini K. Association between bisphosphonates and jaw osteonecrosis: a study in Wistar rats. Head Neck 2011;33:199-207.

24. Xiong $H$, Peng $B$, Zhang $X$, Zhang $X$, Wang L. Effect of an estrogendeficient state and alendronate therapy on bone loss resulting from experimental periapical lesions in rats. J Endod 2007;33:1304-1308.

25. Wayama MT, Yoshimura H, Ohba S, Yoshida H, Matsuda S, Kobayashi J, et al. Diminished progression of periapical lesions with zoledronic acid in ovariectomized rats. J Endod 2015;41:2002-2007.

Received February 22, 2017 Accepted June 23, 2017 